Supporting Information for:

\title{
Improvements to the accuracy of atmospheric oxidized mercury measurements
}

Seth N. Lyman, Lynne E. Gratz, Sarrah M. Dunham-Cheatham, Mae Sexauer Gustin, and Adriel Luippold

Comprising seven pages, eleven figures, and two tables

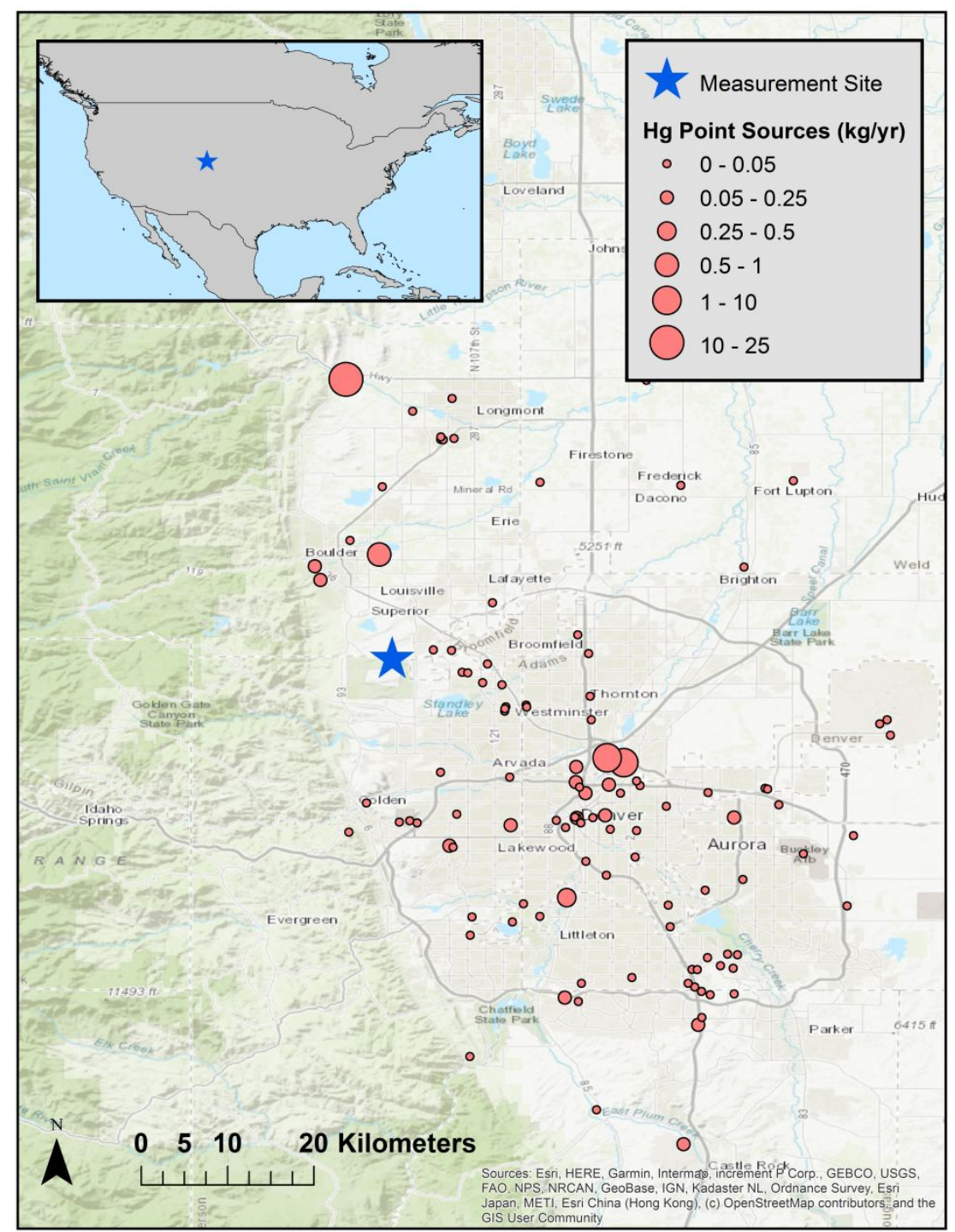

Figure S1. Map of the sampling location and the surrounding area. 


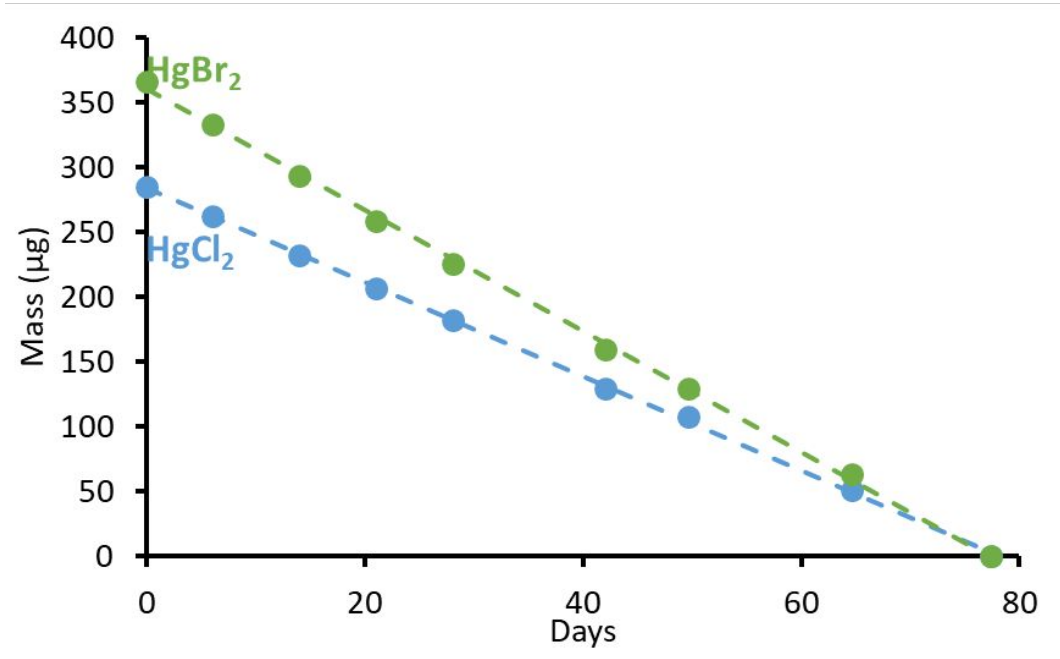

Figure S2. Change in mass over time for two permeation tubes $\left(\mathrm{HgBr}_{2}\right.$ and $\left.\mathrm{HgCl}_{2}\right)$ constructed of PTFE tubing with $0.2 \mathrm{~mm}$ wall thickness.

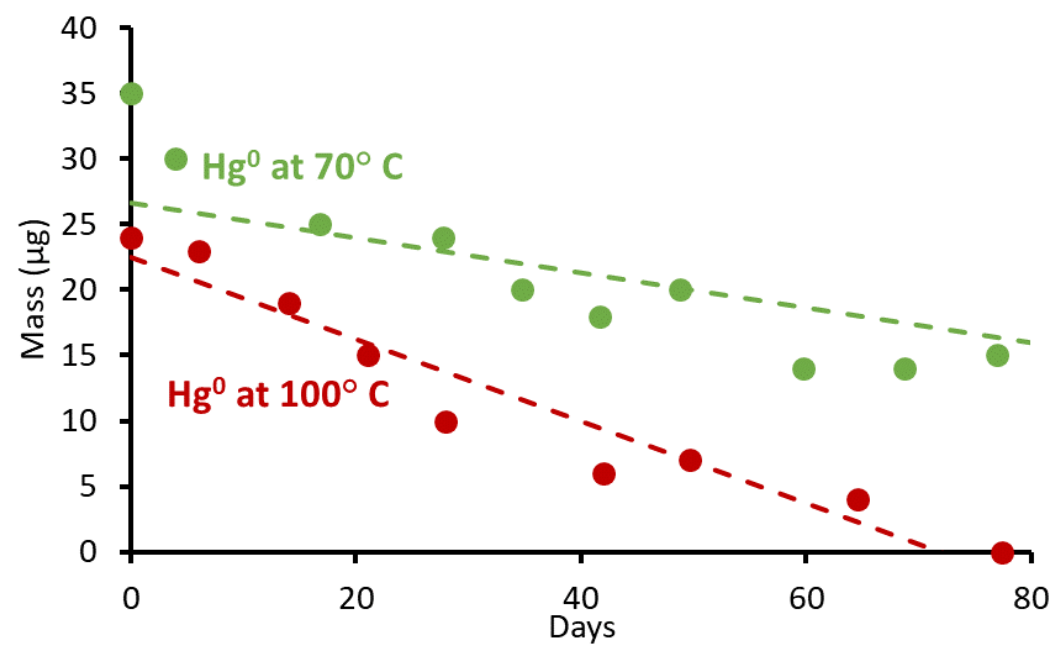

Figure S3. Change in mass over time for an $\mathrm{Hg}^{0}$ permeation tube constructed of PTFE tubing with $0.2 \mathrm{~mm}$ wall thickness. The permeable area was a $1 \mathrm{~mm}$ diameter circle (see methods for more information). The temperatures indicated are the temperature of the permeation oven. 


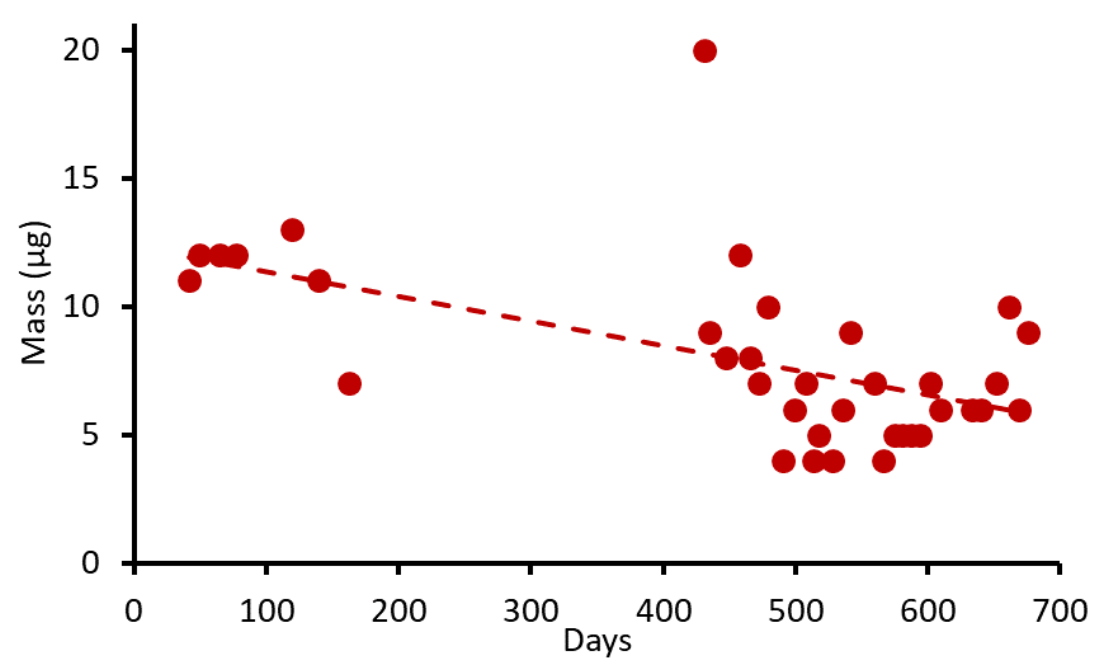

Figure S4. Change in mass over time for an empty (blank) permeation tube constructed of PTFE tubing with $0.2 \mathrm{~mm}$ wall thickness.

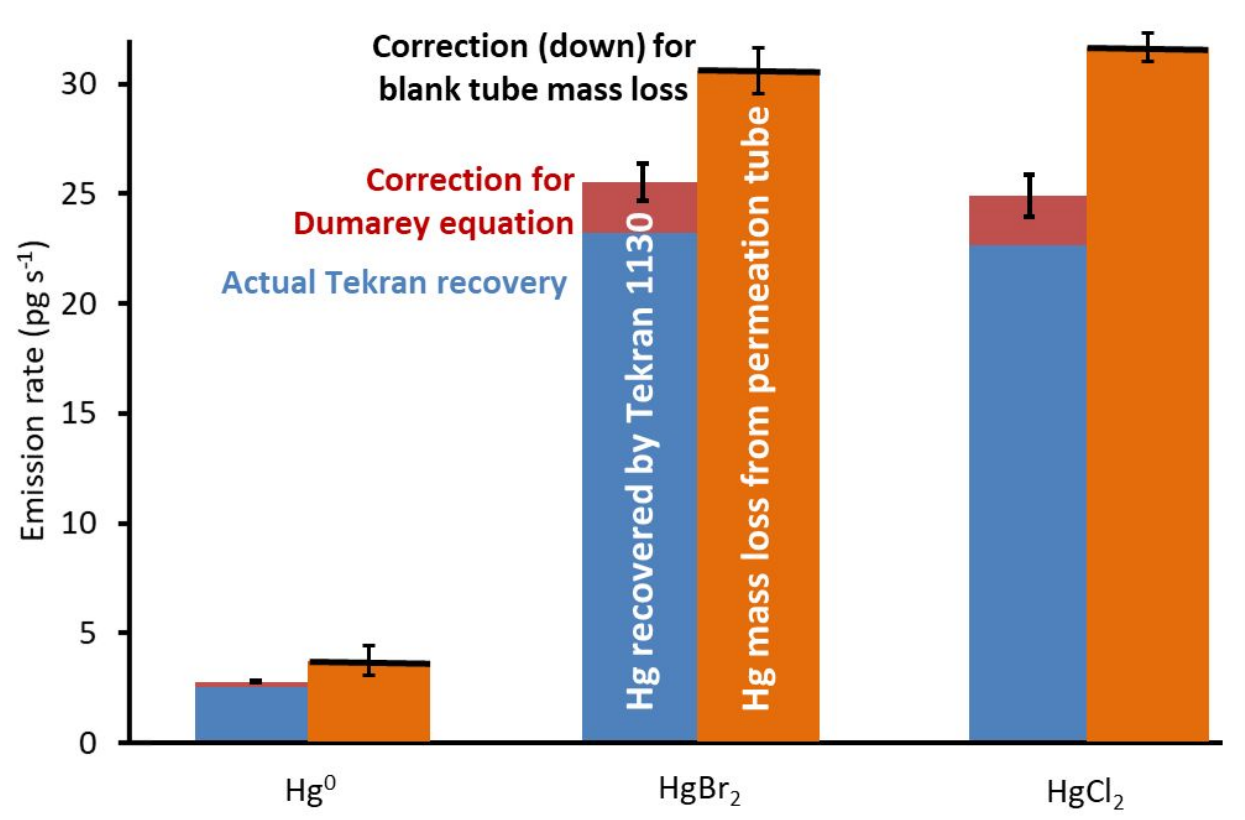

Figure S5. Emission rate of total $\mathrm{Hg}$ from permeation tubes constructed from $0.2 \mathrm{~mm}$ PTFE tubing, as determined by the loss of mass from the tubes over time and as determined by the amount of $\mathrm{Hg}^{0}$ and $\mathrm{Hg}^{\mathrm{II}}$ recovered from the calibrator by the laboratory Tekran 2537/1130 system while the system sampled air scrubbed with an activated carbon cartridge. See the text for a discussion of the correction techniques applied. Whiskers show 95\% confidence intervals. 


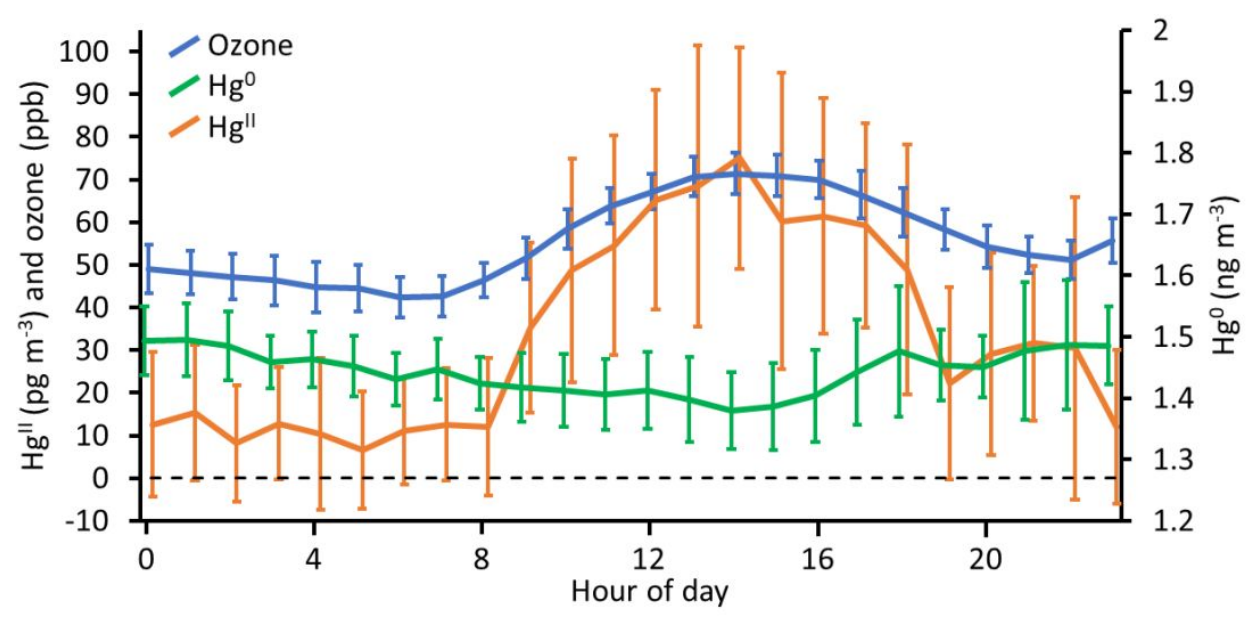

Figure S6. Diurnal plot of average $\mathrm{Hg}^{\mathrm{II}}$, $\mathrm{Hg}^{\mathbf{0}}$, and ozone during the field campaign (mercury measurements are from the dual-channel system). Whiskers represent $95 \%$ confidence intervals.

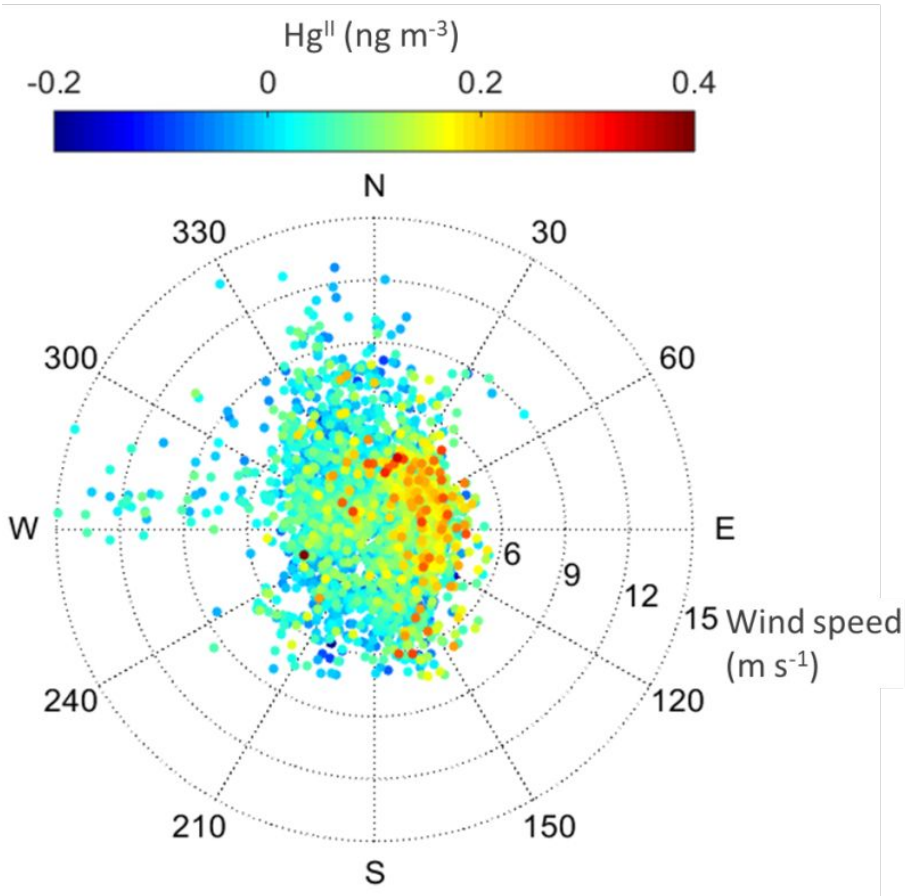

Figure S7. Wind rose plot of 10-min $\mathrm{Hg}^{\mathrm{II}}$ measurements. The position of each dot in the wind rose indicates the wind direction when the measurement was collected. The distance of each dot from the center indicates the wind speed when the measurement was collected. The color of each dot indicates the $\mathrm{Hg}^{\mathrm{II}}$ concentration. 


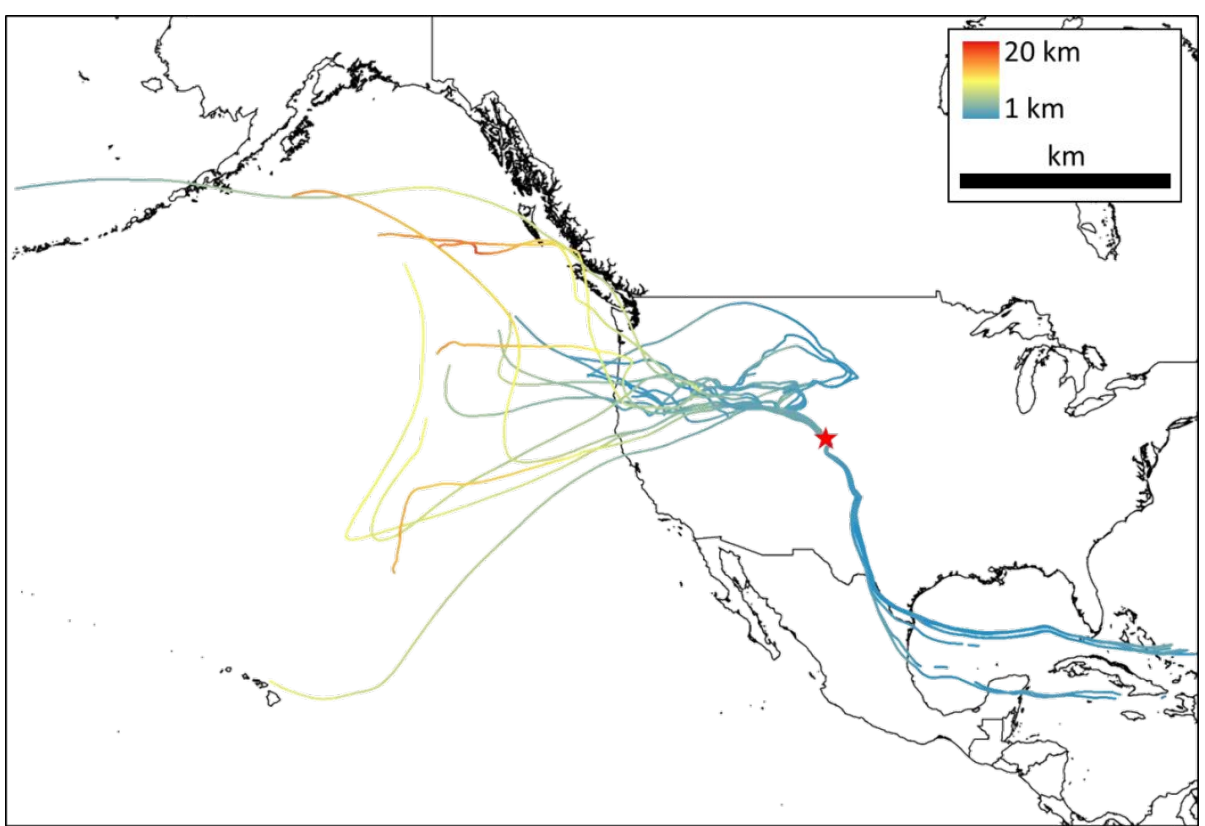

Figure S8. 168-hr HYSPLIT ensemble back trajectories ending at 14:00 local standard time on 8 August 2018, a time with low $\mathrm{Hg}^{\mathrm{II}}$ (afternoon average $<0 \mathrm{pg} \mathrm{m}^{-3}$ ).

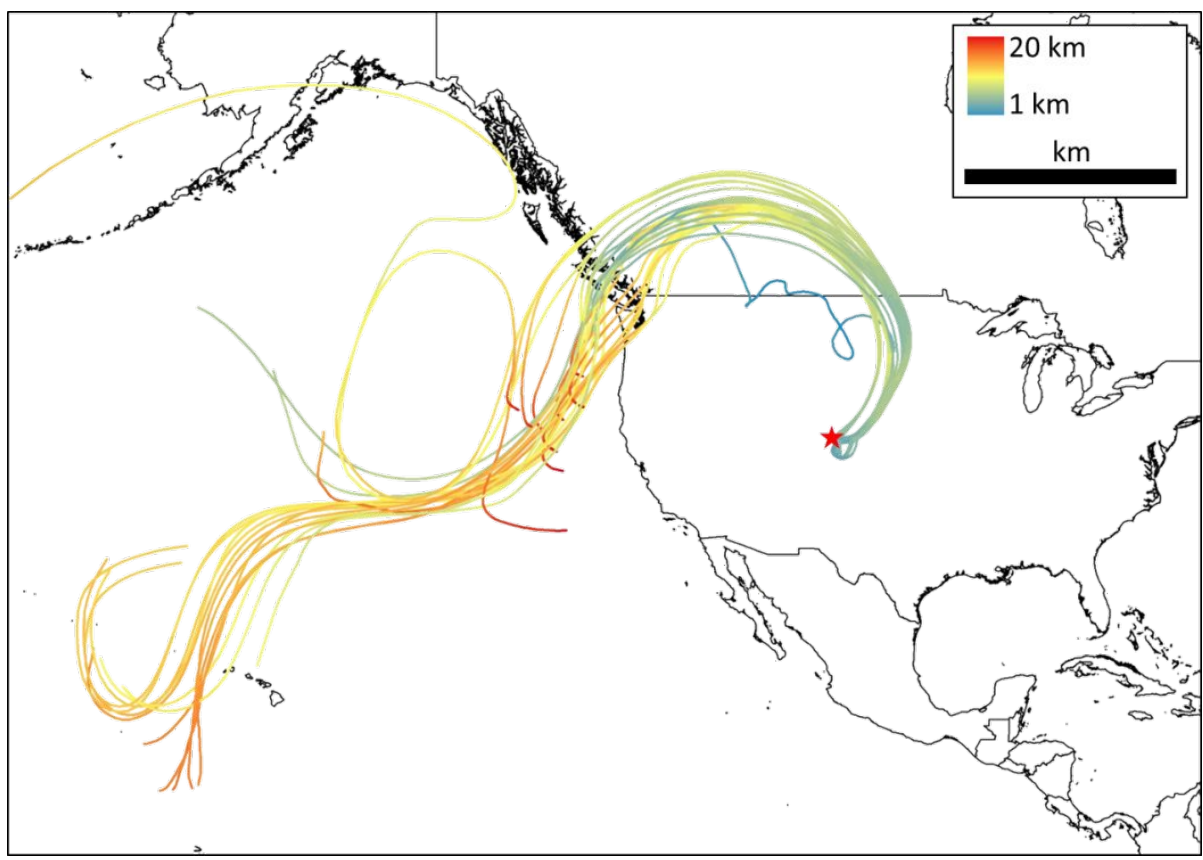

Figure S9. 168-hr HYSPLIT ensemble back trajectories ending at 14:00 local standard time on 11 August 2018, a time with high $\mathrm{Hg}^{\mathrm{II}}$ (afternoon average of $151 \mathrm{pg} \mathrm{m}^{-3}$ ). 


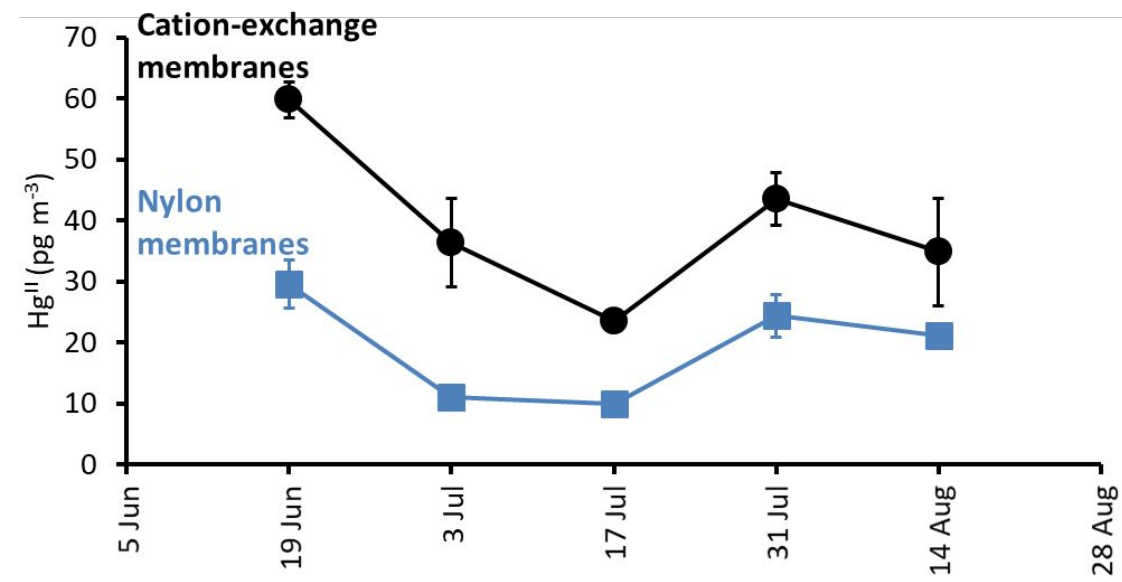

Figure S10. HgII concentrations measured on cation-exchange and nylon membranes with the UNR-RMAS. Dates represent the start date of two-week sampling periods.

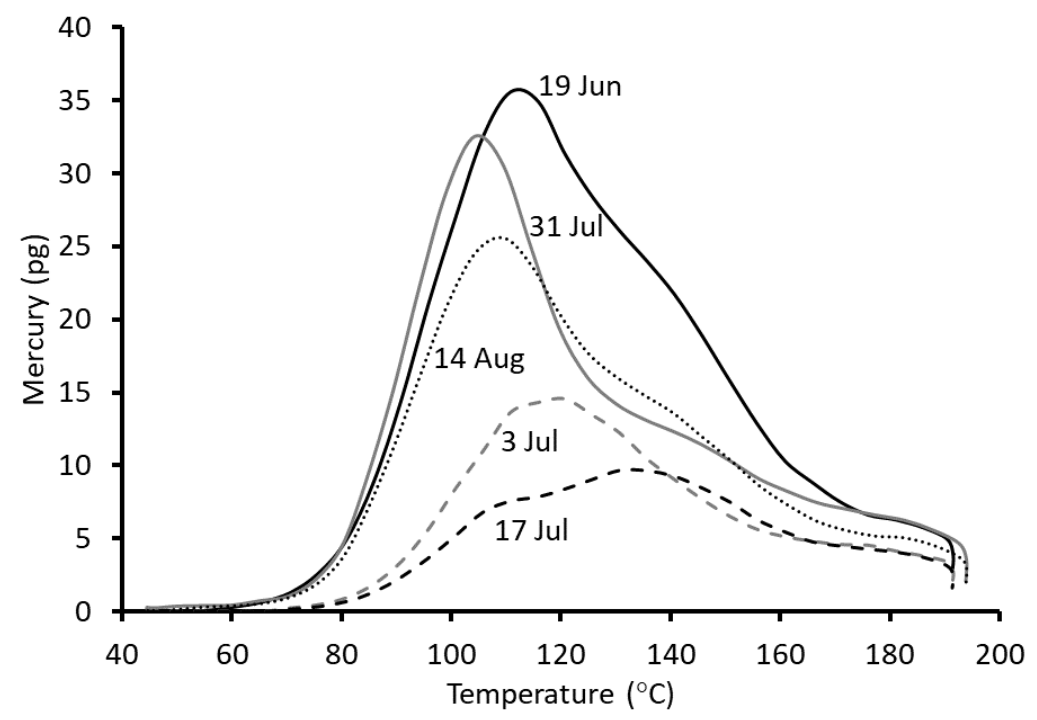

Figure S11. Thermal desorption profiles of nylon membranes from the UNR-RMAS. Each curve represents the mean of replicate $(n=3)$ membranes, and dates represent the start date of the 2week sampling period. $\mathrm{Hg}^{\mathrm{II}}$ compounds containing halogens peak at $90-110^{\circ} \mathrm{C}$, nitrogencontaining compounds peak at $130^{\circ} \mathrm{C}$, and sulfur-containing compounds peak at $180-190^{\circ} \mathrm{C} .33$

Table S1. Mass loss rates for the permeation tubes used in this study. Rates are not blankcorrected. All mass loss slopes were statistically significant.

\begin{tabular}{|l|l|l|l|l|}
\hline Contents & $\begin{array}{l}\text { Tube } \\
\text { thickness } \\
(\mathbf{m m})\end{array}$ & $\begin{array}{l}\text { Tube } \\
\text { material }\end{array}$ & $\begin{array}{l}\text { Mass loss rate } \\
\text { (Hg mass } \\
\text { only; pg sec }\end{array}$ & $\begin{array}{l}\mathbf{r}^{\mathbf{2}} \text { for } \\
\text { mass loss } \\
\text { slope }\end{array}$ \\
\hline $\mathrm{HgCl}_{2}$ & 0.8 & PFA & $2.3 \pm 0.4$ & 0.97 \\
\hline $\mathrm{HgBr}_{2}$ & 0.8 & PFA & $1.2 \pm 0.3$ & 0.87 \\
\hline $\mathrm{Hg}^{0}$ & 0.8 & PFA & $0.4 \pm 0.6$ & 0.18 \\
\hline $\mathrm{HgCl}_{2}$ & 0.2 & PTFE & $31.1 \pm 0.6$ & 1.00 \\
\hline $\mathrm{HgBr}_{2}$ & 0.2 & PTFE & $30.0 \pm 1.0$ & 1.00 \\
\hline $\mathrm{Hg}^{0}$ & 0.2 & PTFE & $3.6 \pm 0.6$ & 0.93 \\
\hline Empty & 0.2 & PTFE & $0.1 \pm 0.1$ & 0.31 \\
\hline
\end{tabular}


Table S2. Field campaign variable averages $\pm 95 \%$ confidence intervals. Afternoon was defined as 13:00 to 17:00, local standard time. Correlations (Pearson $\mathrm{r}$ ) with $\mathrm{Hg}^{\mathrm{II}}$ are shown in parentheses, and bold correlations are statistically significant.

\begin{tabular}{|l|l|l|l|}
\hline Parameter & Units & Entire campaign & Afternoon only \\
\hline $\mathrm{THg}(\mathrm{THg}$ system) & $\mathrm{ng} \mathrm{m}^{-3}$ & $1.47 \pm 0.01(0.03)$ & $1.51 \pm 0.02(\mathbf{- 0 . 3 4})$ \\
\hline $\mathrm{THg}$ (dual-channel) & $\mathrm{ng} \mathrm{m}^{-3}$ & $1.48 \pm 0.01(-0.02)$ & $1.46 \pm 0.03(-0.23)$ \\
\hline $\mathrm{Hg}^{0}$ & $\mathrm{ng} \mathrm{m}^{-3}$ & $1.44 \pm 0.01(\mathbf{- 0 . 4 1})$ & $1.39 \pm 0.02(\mathbf{- 0 . 6 3})$ \\
\hline $\mathrm{Hg}^{\mathrm{II}}$ & $\mathrm{pg} \mathrm{m}^{-3}$ & $34 \pm 5$ & $67 \pm 14$ \\
\hline $\mathrm{Ozone}^{\mathrm{p}}$ & $\mathrm{ppb}$ & $55.9 \pm 1.3(\mathbf{0 . 5 5})$ & $70.7 \pm 2.2(\mathbf{0 . 3 8})$ \\
\hline $\mathrm{CO}_{2}$ & $\mathrm{ppm}$ & $420 \pm 1(\mathbf{- 0 . 4 2})$ & $416 \pm 1(\mathbf{- 0 . 2 8})$ \\
\hline Temperature & ${ }^{\circ} \mathrm{C}$ & $21.9 \pm 0.5(\mathbf{0 . 6 4})$ & $27.6 \pm 0.8(\mathbf{0 . 5 1})$ \\
\hline Relative humidity & $\%$ & $46.6 \pm 2.0(\mathbf{- 0 . 5 9})$ & $32.1 \pm 3.7(\mathbf{- 0 . 4 9})$ \\
\hline Wind speed & $\mathrm{m} \mathrm{s}^{-1}$ & $3.6 \pm 0.2(-0.04)$ & $3.6 \pm 0.3(-0.16)$ \\
\hline
\end{tabular}

